\title{
Adsorption and Decomposition of Peroxides on the Surfaces of Dispersed Oxides $\mathrm{Fe}_{2} \mathrm{O}_{3}, \mathrm{Cr}_{2} \mathrm{O}_{3}$ and $\mathrm{V}_{2} \mathrm{O}_{5}$
}

\author{
Volodymyr Dutka *, Olena Aksimentyeva, Nataliya Oshchapovska, Yaroslav Kovalskyi (D) and \\ Halyna Halechko
}

Department of Physical and Colloid Chemistry, Ivan Franko National University of Lviv, Kyryla\&Mefodia str. 6, 79005 Lviv, Ukraine; aksimen@ukr.net (O.A.); natalia.matsyuk88@ukr.net (N.O.); yakovalskyi@gmail.com (Y.K.); gzastavska@gmail.com (H.H.)

* Correspondence: vdutka@ukr.net; Tel.: +380993081472

Received: 17 December 2018; Accepted: 16 January 2019; Published: 17 January 2019

\begin{abstract}
The adsorption of peroxides on dispersed oxides $\mathrm{Fe}_{2} \mathrm{O}_{3}, \mathrm{Cr}_{2} \mathrm{O}_{3}$ and $\mathrm{V}_{2} \mathrm{O}_{5}$ was studied. It is shown that the adsorption of peroxides is described by the Langmuir equation. The adsorption of benzoyl peroxide grows within $\mathrm{Fe}_{2} \mathrm{O}_{3}<\mathrm{Cr}_{2} \mathrm{O}_{3}<\mathrm{V}_{2} \mathrm{O}_{5}$. Adsorption-desorption equilibrium constants (K) for $\mathrm{Cr}_{2} \mathrm{O}_{3}$ and $\mathrm{V}_{2} \mathrm{O}_{5}$ are the same, but for $\mathrm{Fe}_{2} \mathrm{O}_{3}$ this value is 6 times higher. The decomposition of peroxides is observed in the solution and on the surface of adsorbents. The effective activation energy (E) of the thermal decomposition of peroxides in the studied systems is in the range of $80-140 \mathrm{~kJ} / \mathrm{mol}$. The activation energy of degradation of peroxides on the surface $\left(\mathrm{E}_{\mathrm{s}}\right)$ of the dispersed oxides studied is lower. The degradation reaction of peroxides on the surface of $\mathrm{Fe}_{2} \mathrm{O}_{3}$ and $\mathrm{V}_{2} \mathrm{O}_{5}$ has an oxidation-reducing nature, during which free radicals are produced. On the surface of $\mathrm{Cr}_{2} \mathrm{O}_{3}$, there is a heterolytic decay of peroxides. The parameters of the reaction of peroxides decomposition are found. The decomposition of peroxides in the presence of $\mathrm{Fe}_{2} \mathrm{O}_{3}, \mathrm{Cr}_{2} \mathrm{O}_{3}$ and $\mathrm{V}_{2} \mathrm{O}_{5}$ in styrene is accompanied by the formation of polystyrene both in the solution and on the surface of the adsorbent.
\end{abstract}

Keywords: adsorption; peroxides; decomposition of peroxides; energy of activation; polymerization; polystyrene

\section{Introduction}

Hybrid organic-mineral composites are produced with the incorporation of inorganic fillers in the structure of polymer [1-6]. Polymer-mineral composites have unique properties, therefore, the study of their synthesis and physicochemical properties is urgently required. The polymer matrix incorporated with inorganic particles forms the micro/nanocomposites that can be used in different fields of industry [2]. These composites may be used as optical materials for modern optics and optoelectronic devices [3]. Conjugated polymers with different inorganic nanoparticles can form the hybrid structure with electrical conductivity and catalytic functions [4]. The composite of polymers with dispersive metal oxides takes a special place among industrial polymer-mineral composites [5]. The filler in a polymeric composite performs a function of the pigment or stabilizer. The effective method to produce polymer composites with inorganic metal oxide dispersion is "in situ" polymerization. With this method the formation of polymer matrix is realized during monomer polymerization in the presence of dispersive mineral filler [1,6]. The highly developed surface of the mineral filler affects the parameters of the polymerization process due to the adsorption of the monomer and the peroxide radical initiator [4]. This surface can change the molecular masses and the molecular weight distribution of the polymer formed under these conditions. Mineral filler affects the rate of thermal decomposition of peroxide compounds used to initiate polymerization. 
Understanding the nature of the interfacial region between an organic peroxide initiator and an inorganic filler component is essential for determining how this region affects the mechanism of polymerization and overall bulk properties of the organic/inorganic hybrid composite material. In this work, polystyrene was used as the model polymer matrix coupled with metal-oxide fillers such as transitional metal oxides $\mathrm{Fe}_{2} \mathrm{O}_{3} ; \mathrm{Cr}_{2} \mathrm{O}_{3}$ and $\mathrm{V}_{2} \mathrm{O}_{5}$ widely used as mineral pigments and catalysts [6].

The aim of our work was to study the adsorption of peroxide initiators on the surface of dispersed oxides, thermolysis and polymerization in such systems.

\section{Materials and Methods}

The investigation of adsorption and thermal decomposition of peroxides was carried out in a styrene solution with an ampoule technique [7]. The styrene was purified and fractionated in the argon atmosphere. The adsorbent was placed in the ampoule and the styrene solution and a certain amount of peroxide was added. The ampoules were rotated during the experiment. The rotor placed in the water thermostat continuously stirred the mixture reaction. The temperature was kept constant within $\pm 0.05 \mathrm{~K}$. At certain intervals, the ampoules were removed from the thermostat, cooled quickly and then the content of the undecomposed peroxide was analyzed with the iodometric method [8].

The adsorption experiments were carried out at the temperature of $303 \mathrm{~K}$. No decomposition of the peroxides in styrene solutions or on the surface of the examined fillers was observed in the temperature range of $303-313 \mathrm{~K}$. The thermal decomposition of peroxides was carried out in the temperature range of $338-363 \mathrm{~K}$.

The disperse oxides $\mathrm{Fe}_{2} \mathrm{O}_{3} ; \mathrm{Cr}_{2} \mathrm{O}_{3}$ and $\mathrm{V}_{2} \mathrm{O}_{5}$ (Sigma-Aldrich is now MERCK) were heated at $700 \mathrm{~K}$ in vacuum for $6 \mathrm{~h}$ to remove the absorbed moisture. The surface areas of investigated adsorbents $\mathrm{Fe}_{2} \mathrm{O}_{3}, \mathrm{Cr}_{2} \mathrm{O}_{3}$ and $\mathrm{V}_{2} \mathrm{O}_{5}$ were $75.0,80.0$ and $65.0 \mathrm{~m}^{2} / \mathrm{g}$, respectively. The specific surface arrears of $\mathrm{Fe}_{2} \mathrm{O}_{3}, \mathrm{Cr}_{2} \mathrm{O}_{3}$ and $\mathrm{V}_{2} \mathrm{O}_{5}$ were determined using low-temperature adsorption of nitrogen (BET).

The purified benzoyl peroxide (BP) was used in the most experiments [8]. The oligomeric peroxide of sebacic acid (OPSA) and didecanoyl diperoxyadipinat (DP) were used in some experiments [9].

\section{Results and Discussion}

The adsorption of peroxides is well described by the Langmuir equation. The isotherms of the adsorption of BP on the investigated disperse minerals are shown in Figure 1. These dependences are linear in coordinates $1 / \mathrm{A}$ from $1 / \mathrm{C}$, which allowed us to determine the maximum adsorption $\left(\mathrm{A}_{\infty}\right)$ and the adsorption-desorption equilibrium constant (K).

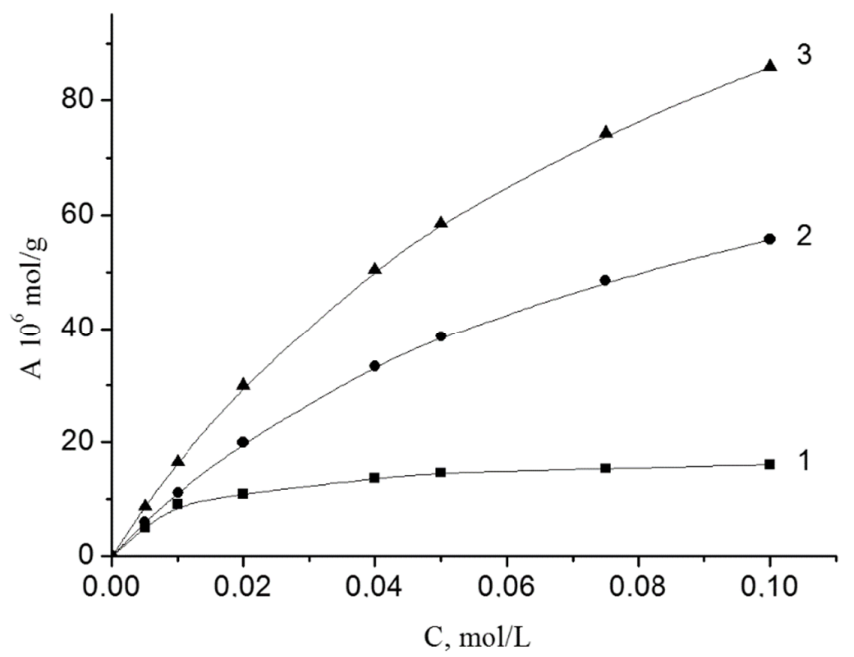

Figure 1. Isotherms of BP adsorption from styrene on the surface of iron (1), chromium (2) and vanadium (3) oxides at $303 \mathrm{~K}$. The content of oxides was $1 \mathrm{~g} / \mathrm{L}$. 
The adsorption-desorption equilibrium was established in 10-15 min. The parameters of the adsorption process are show in Table 1.

Table 1. Physicochemical parameters of BP adsorption on surfaces of $\mathrm{Fe}_{2} \mathrm{O}_{3}, \mathrm{Cr}_{2} \mathrm{O}_{3}$ and $\mathrm{V}_{2} \mathrm{O}_{5}$ from styrene at $303 \mathrm{~K}$.

\begin{tabular}{ccccccccc}
\hline Adsorbent & $\mathbf{A}_{\boldsymbol{\infty}} \cdot \mathbf{1 \mathbf { 0 } ^ { \mathbf { 6 } }}, \mathbf{\mathbf { m o l }} \mathbf{\mathbf { g }}$ & $\mathbf{S}, \AA^{\mathbf{2}}$ & $\mathbf{K}, \mathbf{m}^{\mathbf{3}} / \mathbf{k m o l}$ & $-\mathbf{\Delta G}, \mathbf{k J} / \mathbf{m o l}$ & $\mathbf{Q}_{\mathbf{i}}, \mathbf{J} / \mathbf{g}$ & $\mathbf{Q}_{\mathbf{s}}, \mathbf{J} / \mathbf{g}$ & $\mathbf{Q}_{\mathbf{a}}, \mathbf{J} / \mathbf{g}$ & $\mathbf{q}_{\mathbf{a}}, \mathbf{k J} / \mathbf{m o l}$ \\
\hline $\mathrm{Fe}_{2} \mathrm{O}_{3}$ & 1.81 & 91 & 75.63 & 10.7 & 2.87 & 2.69 & 0.18 & 10 \\
$\mathrm{Cr}_{2} \mathrm{O}_{3}$ & 10.1 & 16 & 12.32 & 6.2 & 7.82 & 5.96 & 1.86 & 18 \\
$\mathrm{~V}_{2} \mathrm{O}_{5}$ & 16.2 & 10 & 11.31 & 6.0 & 11.07 & 7.59 & 3.49 & 22 \\
\hline
\end{tabular}

The adsorption of BP grows within $\mathrm{Fe}_{2} \mathrm{O}_{3}<\mathrm{Cr}_{2} \mathrm{O}_{3}<\mathrm{V}_{2} \mathrm{O}_{5}$. Adsorption-desorption equilibrium

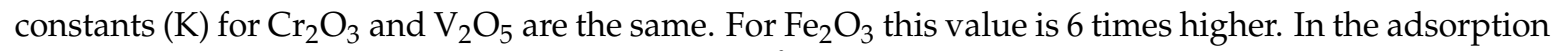
layer, the BP molecule areas (S) are 16,10 and $91 \AA^{2}$. The values of $\Delta \mathrm{G}$ were calculated based on the numerical values of $\mathrm{K}$. The values of $\Delta \mathrm{G}$ are similar $(-6.2$ and $-6.0 \mathrm{~kJ} / \mathrm{mol})$ for $\mathrm{Cr}_{2} \mathrm{O}_{3}$ and $\left.\mathrm{V}_{2} \mathrm{O}_{5}\right)$. For $\mathrm{Fe}_{2} \mathrm{O}_{3}$ the value of $\Delta \mathrm{G}$ has a much greater numerical value $(-10.7 \mathrm{~kJ} / \mathrm{mol})$.

The heat of adsorption $\left(\mathrm{Q}_{\mathrm{a}}\right)$ is an important parameter of the adsorption process. The numerical values of $Q_{a}$ are shown in Table 1. To determine the numerical values of the adsorption heat, it is necessary to determine the heat of wetting $\left(\mathrm{Q}_{\mathrm{s}}\right)$. The heat of adsorption can be calculated from the difference between the wetting heat and the integral heat $\left(\mathrm{Q}_{\mathrm{i}}\right)$ since physical adsorption and chemisorptions are thermodynamically practically inseparable. In most cases they are characterized by the different order of the magnitude value of the differential molar adsorption heat $\mathrm{q}_{\mathrm{a}}$. To determine the nature of adsorption, the value $\mathrm{q}_{\mathrm{a}}$ was calculated (Equation (1)):

$$
\mathrm{q}_{\mathrm{a}}=\mathrm{Q}_{\mathrm{a}} / \mathrm{A}_{\infty}
$$

The calculated values of $\mathrm{q}_{\mathrm{a}}$ for these systems are 10-22 $\mathrm{kJ} / \mathrm{mol}$ according to the physical adsorption (Table 1).

The thermal decomposition of the peroxides is well described by the kinetic equation of the first-order. In all cases, the reaction rate of the thermal decomposition of peroxide grows with the addition of dispersed oxides. Thermolysis of peroxides in a heterogeneous system happens under two thermodynamically distinct conditions-in the volume of the solvent and on the interface between the phases. The structure of the peroxide and the surface of the disperse oxide affects the rate of the destruction.

The kinetic curves of the thermal decomposition of BP from content of $\mathrm{Fe}_{2} \mathrm{O}_{3}$ are given in Figure 2.

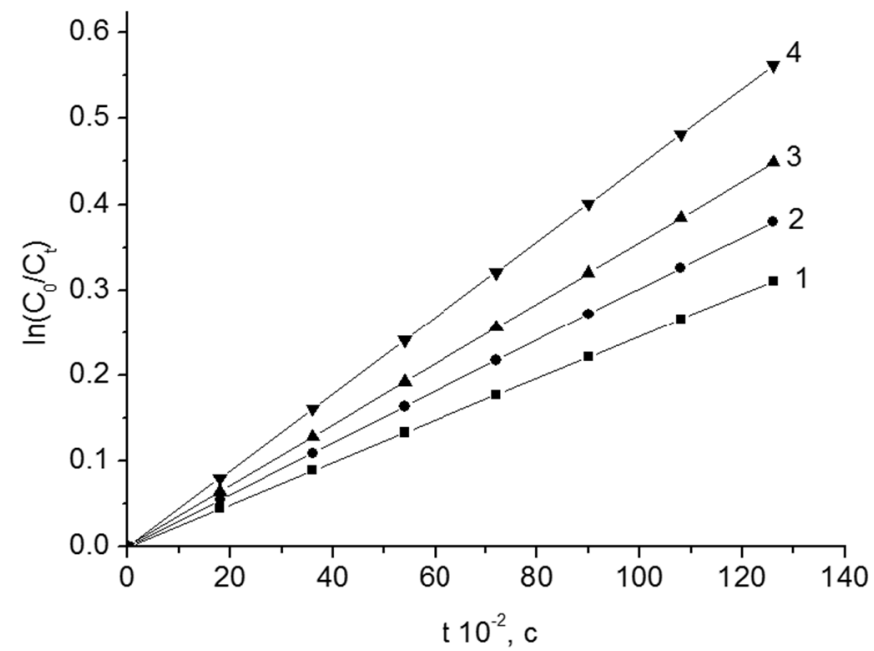

Figure 2. The kinetic curves of the thermal decomposition of $\mathrm{BP}$ in styrene. $\mathrm{T}=348 \mathrm{~K} . \mathrm{Fe}_{2} \mathrm{O}_{3}$ content, wt.\%: $1-0 ; 2-4.0 ; 3-9.2 ; 4-15.3$. 
The process of thermal decomposition is described by the equation of the first-order reaction rate. According to the slopes of the dependencies (Figure 2), the observed rate constants (k) of the thermal decomposition of peroxides were found. The total rate constant of the reaction of thermolysis grows with the increase of the content of disperse oxide in the system. The constants of the rate of thermal decomposition of $\mathrm{BP}$ and other peroxide compounds in the presence of $\mathrm{Fe}_{2} \mathrm{O}_{3}, \mathrm{Cr}_{2} \mathrm{O}_{3}$ and $\mathrm{V}_{2} \mathrm{O}_{5}$ are shown in Tables 2-4. The effective energies of activation of the thermal decomposition process (E) were calculated with the temperature dependences of $k$. The decomposition of peroxide compounds occurs in the solution and on the surface of the disperse oxides. Proceeding from this, an expression for the specific rate of the process is as follows:

$$
\mathrm{k}_{\mathrm{p}}=\mathrm{k}+\mathrm{k}_{\mathrm{s}} \mathrm{S}_{\mathrm{a}} \mathrm{C}^{\rho-1}
$$

where $S_{a}$ is the area of surface of the dispersed phase in 1 liter of mixture, $C$-is the initial concentration of peroxide in the system, $\rho$ is the kinetic order of the reaction of the heterogeneous catalytic decomposition, $\mathrm{k}_{\mathrm{s}}$ is the rate constant of the decomposition of peroxide on the surface of the adsorbent.

Table 2. The kinetic and activation parameters of the reaction of thermal decomposition of BP and OPSA in the presence of chromium oxide.

\begin{tabular}{|c|c|c|c|c|c|c|c|}
\hline \multirow{2}{*}{$\begin{array}{c}\mathrm{Cr}_{2} \mathrm{O}_{3} \text { Content, } \\
\text { wt. } \%\end{array}$} & \multicolumn{6}{|c|}{$\mathrm{k} \cdot 10^{5}, \mathrm{~s}^{-1} ; \Delta \mathrm{k}= \pm 0.03 \mathrm{k}$} & \multirow{2}{*}{$\mathrm{E}, \mathrm{kJ} / \mathrm{mol}$} \\
\hline & $338 \mathrm{~K}$ & $343 \mathrm{~K}$ & $348 \mathrm{~K}$ & $353 \mathrm{~K}$ & $358 \mathrm{~K}$ & $363 \mathrm{~K}$ & \\
\hline \multicolumn{8}{|c|}{$\mathrm{BP}(0.03 \mathrm{~mol} / \mathrm{L})$} \\
\hline 0 & - & 1.35 & 2.46 & 5.41 & - & 18.6 & 137 \\
\hline 1.0 & 0.77 & 1.55 & 3.05 & 5.83 & 10.7 & 20.0 & 132 \\
\hline 2.0 & 0.84 & 1.71 & 3.33 & 6.11 & 12.4 & - & 134 \\
\hline 3.0 & 0.95 & 2.04 & 3.81 & 6.73 & 13.9 & - & 132 \\
\hline \multicolumn{8}{|c|}{ OPSA (0.03 mol/L) } \\
\hline 0 & 3.46 & 6.47 & 11.5 & 21.7 & 38.5 & - & 119 \\
\hline 2.0 & 3.77 & 6.84 & 11.8 & 22.3 & 38.6 & - & 117 \\
\hline
\end{tabular}

Table 3. The kinetic and activation parameters of thermal decomposition of peroxides in styrene in the presence of $\mathrm{Fe}_{2} \mathrm{O}_{3}$. The concentration of peroxide groups- $-0.03 \mathrm{~mol} / \mathrm{L}$.

\begin{tabular}{|c|c|c|c|c|c|c|c|}
\hline \multirow{2}{*}{ Peroxide } & \multirow{2}{*}{$\begin{array}{c}\mathrm{Fe}_{2} \mathrm{O}_{3} \text { Content, } \\
\text { wt. } \%\end{array}$} & \multicolumn{5}{|c|}{$\mathrm{k} \cdot 10^{5}, \mathrm{~s}^{-1} ; \Delta \mathrm{k}= \pm 0.03 \mathrm{k}$} & \multirow{2}{*}{$\begin{array}{c}\mathrm{E}^{*} \\
\mathrm{~kJ} / \mathrm{mol}\end{array}$} \\
\hline & & $338 \mathrm{~K}$ & $343 \mathrm{~K}$ & $348 \mathrm{~K}$ & $353 \mathrm{~K}$ & $358 \mathrm{~K}$ & \\
\hline BP & 0 & - & 1.35 & 2.46 & 5.41 & - & 137 \\
\hline $\mathrm{BP}$ & 4.0 & 0.95 & 1.80 & 3.02 & 5.90 & 9.35 & 116 \\
\hline $\mathrm{BP}$ & 9.2 & 1.40 & 2.31 & 3.56 & 6.52 & 9.42 & 98 \\
\hline $\mathrm{BP}$ & 15.3 & 2.00 & 3.10 & 4.46 & 7.23 & 10.6 & 84 \\
\hline DP & 0 & 1.20 & 2.28 & 5.25 & 10.5 & 18.2 & 140 \\
\hline DP & 4.0 & 1.51 & 2.70 & 5.62 & 10.8 & 18.5 & 129 \\
\hline $\mathrm{DP}$ & 8.0 & 1.85 & 3.10 & 6.04 & 10.8 & 18.8 & 118 \\
\hline OPSA & 0 & 3.46 & 6.47 & 11.5 & 21.7 & 38.5 & 119 \\
\hline OPSA & 4.0 & 3.72 & 6.98 & 11.8 & 22.0 & 39.5 & 116 \\
\hline OPSA & 8.0 & 3.91 & 7.23 & 11.9 & 22.4 & 40.0 & 114 \\
\hline
\end{tabular}

Table 4. The rate constants of thermolysis of $\mathrm{BP}$ in styrene in the presence of $\mathrm{V}_{2} \mathrm{O}_{5}$. Concentration of peroxide groups $-0.03 \mathrm{~mol} / \mathrm{L}$.

\begin{tabular}{|c|c|c|c|c|c|c|}
\hline \multirow{2}{*}{$\mathrm{V}_{2} \mathrm{O}_{5}$ Content, wt. $\%$} & \multicolumn{5}{|c|}{$\mathrm{k} \cdot 10^{5}, \mathrm{~s}^{-1} ; \Delta \mathrm{k}= \pm 0.03 \mathrm{k}$} & \multirow{2}{*}{$\mathrm{E}, \mathrm{kJ} / \mathrm{mol}$} \\
\hline & $328 \mathrm{~K}$ & $333 \mathrm{~K}$ & $338 \mathrm{~K}$ & $343 \mathrm{~K}$ & $348 \mathrm{~K}$ & \\
\hline 3.0 & 0.96 & 1.55 & 2.37 & 3.40 & 5.38 & 80 \\
\hline 6.0 & - & 2.86 & 4.11 & 5.46 & 8.07 & 70 \\
\hline 10.2 & 3.2 & 3.20 & 6.18 & 8.29 & 12.2 & 60 \\
\hline
\end{tabular}


The Equation (2) becomes an Equation (3). This determines the parameters of the heterogeneouscatalytic decomposition:

$$
\ln \left(\mathrm{k}_{\mathrm{p}}-\mathrm{k}\right) / \mathrm{S}_{\mathrm{a}}=\ln _{\mathrm{s}}+(\rho-1) \ln \mathrm{C}
$$

The specific rates of decomposition of peroxides showed that with the increasing of peroxide concentration the numerical values of $\mathrm{k}_{\mathrm{p}}$ decrease. The increase in the concentration of peroxide leads to the decrease in the numerical values of $\mathrm{k}_{\mathrm{p}}$. The dependencies are linear in coordinates of $\ln \left(\mathrm{k}_{\mathrm{p}}-\mathrm{k}\right) / \mathrm{S}_{\mathrm{a}}$ from $f(\ln \mathrm{C})$, which allowed us to determine the parameters of the heterogeneous catalytic process. Defined parameters are given in Table 5.

Table 5. The kinetic and activation parameters of the heterogeneous-catalytic decomposition of peroxides on oxides surface.

\begin{tabular}{|c|c|c|c|c|c|}
\hline Oxides & $\mathrm{T}, \mathrm{K}$ & $\mathrm{g} *, w \mathrm{t} . \%$ & $-\rho$ & ${ }^{* *} \mathrm{k}_{\mathrm{s}} 10^{8}$ & $* * * E_{s}, \mathrm{~kJ} / \mathrm{mol}$ \\
\hline \multicolumn{6}{|c|}{$\mathrm{BP}$} \\
\hline \multirow[t]{2}{*}{$\mathrm{Fe}_{2} \mathrm{O}_{3}$} & 343 & 4.0 & 0.25 & 1.22 & - \\
\hline & & 9.2 & 0.28 & 1.16 & - \\
\hline \multirow[t]{2}{*}{$\mathrm{Fe}_{2} \mathrm{O}_{3}$} & 348 & 4.0 & 0.27 & 1.51 & 45 \\
\hline & & 9.2 & 0.29 & 1.37 & 46 \\
\hline \multirow[t]{2}{*}{$\mathrm{Fe}_{2} \mathrm{O}_{3}$} & 353 & 4.0 & 0.22 & 1.93 & - \\
\hline & & 9.2 & 0.23 & 1.88 & - \\
\hline $\mathrm{Cr}_{2} \mathrm{O}_{3}$ & 348 & 2.0 & 0.13 & 6.1 & 81 \\
\hline $\mathrm{Cr}_{2} \mathrm{O}_{3}$ & 353 & 2.0 & 0.23 & 9.10 & - \\
\hline $\mathrm{V}_{2} \mathrm{O}_{5}$ & 343 & 3.0 & 0.20 & 10.9 & 24 \\
\hline $\mathrm{V}_{2} \mathrm{O}_{5}$ & & 10.2 & 0.22 & 10.3 & - \\
\hline $\mathrm{V}_{2} \mathrm{O}_{5}$ & 348 & 3.0 & 0.27 & 12.3 & - \\
\hline \multicolumn{6}{|c|}{ DP } \\
\hline \multirow[t]{2}{*}{$\mathrm{Fe}_{2} \mathrm{O}_{3}$} & 348 & 4.0 & -0.18 & 3.23 & - \\
\hline & & 8.0 & -0.18 & 3.21 & - \\
\hline \multicolumn{6}{|c|}{ OPSA } \\
\hline $\mathrm{Fe}_{2} \mathrm{O}_{3}$ & 348 & 4.0 & 0.49 & 0.47 & - \\
\hline $\mathrm{Cr}_{2} \mathrm{O}_{3}$ & 348 & 2.0 & 0.28 & 1.55 & - \\
\hline
\end{tabular}

* $\mathrm{g}$-content of dispersed oxide $\mathrm{wt} . \%$; ${ }^{* *}$ the dimension of the constant $\mathrm{k}_{\mathrm{s}}\left(\mathrm{L} / \mathrm{m}^{2} \mathrm{~s}\right)^{*}(1 / \mathrm{mol})^{\rho-1}$; ${ }^{* * *}$ the error of the determination of $\mathrm{E}_{\mathrm{s}} \pm 4.0 \mathrm{~kJ} / \mathrm{mol}$.

The energy of activation of the heterogeneous-catalytic $\left(\mathrm{E}_{\mathrm{S}}\right)$ decomposition of the peroxides was calculated based on the results obtained at different temperatures. The numerical values of activation energy of surface decomposition peroxides $E_{s}$ are much lower than summary energy $E$ determined in homogeneous systems [9]. This points out the oxidation-reducing nature of the decomposition process on the surface of the disperse oxides. The mechanism of heterogeneous-catalytic decomposition depends on the nature of the disperse oxide. The filler increases the polymerization rate of styrene in the presence of $\mathrm{Fe}_{2} \mathrm{O}_{3}$ [10], but $\mathrm{Cr}_{2} \mathrm{O}_{3}$ slightly inhibits the formation of polymer [11]. The adsorption of peroxide initiators and their decay on the surface of $\mathrm{Cr}_{2} \mathrm{O}_{3}$ proceeds along the mechanism of a similar decomposition on the surface of the aerosil [7]. Polymerization of styrene in the presence of $\mathrm{Cr}_{2} \mathrm{O}_{3}$ takes place only in solution. Due to the adsorption of peroxide compounds on the surface of $\mathrm{Cr}_{2} \mathrm{O}_{3}$, the initiator concentration in the solution decreases, therefore, the rate of styrene polymerization is slowed down. 
The free radicals are formed on the surface of $\mathrm{Fe}_{2} \mathrm{O}_{3}$ and $\mathrm{V}_{2} \mathrm{O}_{5}$. They can initiate the polymerization reaction. During the study of the thermal decomposition of peroxides in styrene in the presence of $\mathrm{V}_{2} \mathrm{O}_{5}$, a change in the color of the adsorbent is observed, indicating the oxidation-reducing nature of the initiator's decomposition on the surface. The reaction of the decomposition of peroxides on the surface of $\mathrm{Cr}_{2} \mathrm{O}_{3}$ does not lead to the formation of free radicals.

\section{Conclusions}

Thus, the adsorption of some organic peroxides on the surface of dispersed $\mathrm{Fe}_{2} \mathrm{O}_{3}, \mathrm{Cr}_{2} \mathrm{O}_{3}$ and $\mathrm{V}_{2} \mathrm{O}_{5}$ was studied. It is shown that the adsorption of peroxides is described by the Langmuir equation. The calculated values of the differential molar adsorption heat $\mathrm{q}_{\mathrm{a}}$ for these systems are $10-22 \mathrm{~kJ} / \mathrm{mol}$ according to the physical adsorption. The surfaces of the studied disperse inorganic oxides affect the process of thermal decomposition of diacylic peroxides. The thermal decomposition of the peroxides is well described by the kinetic equation of the first-order. In all cases, the reaction rate of the thermal decomposition of peroxide grows with the addition of dispersed oxides. The numerical values of activation energy of surface decomposition peroxides $E_{\mathrm{s}}$ are much lower than summary energy of decomposition E determined in homogeneous systems. This points out the oxidation-reducing nature of the decomposition process on the surface of the disperse oxides.

Depending on the nature of the surface of the oxide, the peroxide decomposes homolytically—with the formation of free radicals, or heterolytically—by inhibiting the polymerization of styrene on the surface. In all cases, during the thermal decomposition of peroxides, polymer-mineral composites are formed.

Author Contributions: Conceptualization, V.D. and O.A.; methodology, V.D.; software, Y.K.; validation, N.O., Y.K. and H.H.; formal analysis, N.O.; investigation, Y.K.; resources, H.H.; data curation, N.O. and H.H.; writing-original draft preparation, V.D.; writing—review and editing, O.A.; visualization, Y.K.; supervision, O.A.; project administration, V.D.; funding acquisition, O.A.

Funding: This research received no external funding.

Conflicts of Interest: The authors declare no conflict of interest.

\section{References}

1. Berlin, A. Polymer Composite Materials: Structure, Properties, Technology; Profession: St. Petersburg, Russia, 2011. (In Russian)

2. Bryk, M. Polymerization on the Solid Surface of Inorganic Substances; Nauk. Dumka: Kiev, Ukraine, 1981. (In Russian)

3. Nedilko, S.G. Polymer-Oxide Composites: Toward New Optical Materials. Acta Phys. Pol. A 2018, 133, 829-837. [CrossRef]

4. Voronov, S.A.; Varvarenko, S.M. Peroxide-Containing Macromolecules at the Interface of the Phases; Lviv Polytech: Lviv, Ukraine, 2011. (In Ukrainian)

5. Kumar, V.; Kalia, S.; Swart, H.C. Conducting Polymer Hybrids; Springer Series on Polymer and Composite Materials; Springer International Publishing: Cham, Switzerland, 2017; ISBN 978-3-319-46458-9.

6. Miller, J.D.; Drelich, J. Critical review of wetting and adhesion phenomena in the preparation of polymer-mineral composites. Min. Met. Process. 1995, 12, 197-204. [CrossRef]

7. Tsvetkov, N.S.; Kovalskii, Y.P. Kinetics of thermal decomposition of diacyl peroxides in the presence of aerosil. React. Kinet. Catal. Lett. 1982, 21, 335-340. [CrossRef]

8. Antonovskii, V.; Buzulanova, M. Analytical Chemistry of Organic Peroxides; Khimia: Moscow, Russia, 1978. (In Russian)

9. Dutka, V.; Midyna, G.; Dutka, Y.; Pal'chikova, E. Solvents Effect on the Rate of Thermal Decomposition of Diacyl Peroxides. Rus. J. Gen. Chem. 2018, 88, 632-640. [CrossRef] 
10. Dutka, V. Styrene polymerization in presence of the disperse iron oxide. Ukr. Polym. J. 2013, 35, $136-139$. (In Ukrainian)

11. Dutka, V.; Kovalskyi, Y.; Dutka, Y. Features of styrene polymerization in the presence of the disperse chromium oxide. Ukr. Polym. J. 2014, 36, 207-212. (In Ukrainian) 